\title{
Adding up fine motor skills: developmental relations between manual dexterity and numerical abilities
}

\author{
Venera Gashaj and Dragan Trninić \\ Swiss Federal Institute of Technology (ETH) Zurich
}

\begin{abstract}
We explore the relationship between mathematical skills and motor skills across three age groups of normally developing children. The existence of such a relationship is postulated in classical accounts of human development. In contemporary research, the existence of a relationship between motor development and the development of abstract concepts may form a crucial piece of evidence for theories of embodied cognition. Existing studies suggest a link between fine motor skills and various numerical and mathematical tasks in young children; however, there are few attempts to measure the strength of this relationship across different ages. We use a cross-sectional design to investigate the link between fine motor and mathematical skills in children in Kindergarten, $2^{\text {nd }}$ grade, and $4^{\text {th }}$ grade. The results show that correlational patterns vary in the three ages; while in Kindergarten manual dexterity of the dominant hand is related to math skills, in $2^{\text {nd }}$ grade the manual dexterity of the nondominant hand is related to math skills, and finally in $4^{\text {th }}$ grade no such correlations are observable.
\end{abstract}

Keywords: fine motor skills, mathematical skills, cross-sectional design, embodied cognition

Corresponding author: Venera Gashaj, Swiss Federal Institute of Technology (ETH), Clausiusstrasse 59, 8006 Zürich, Switzerland, E-mail: venera.gashaj@gess.ethz.ch 


\section{Introduction}

Empirical studies indicate a positive relation between motor and cognitive development (e.g., van der Fels et al., 2015; Wassenberg et al., 2005), as predicted by classical theories of human development (e.g., Piaget \& Inhelder, 1966; Vygotsky, 1997). Yet the extent and nature of apparent relationships between motor skill and cognitive abilities remains largely uncharted in both developmental psychology (Grissmer et al., 2010) and human movement sciences (Oberer, Gashaj, \& Roebers, 2017). This paper reports on a crosssectional study investigating the relations of fine motor skills and mathematical abilities in children at ages 6,8 , and 10 . The exploration is navigated from the theoretical perspective of embodied cognition, which we discuss in the following section.

\section{Embodied Cognition}

Embodied cognition can be understood as a related set of ideas emerging as alternatives to the dominant artificial intelligence metaphor of the mind. Standard theories of cognition had assumed that knowledge resides in amodal cognitive systems (i.e., symbolic information processing) separate from the brain's systems for perception and action (Barsalou, 2008). One consequence of this apparent distinction between the body and the mind can be found in the disjointed development of cognitive psychology and conceptual change on the one hand, and human movement sciences and motor skill learning on the other. In contrast, embodied cognition foregrounds the idea of cognition as constituted by modalities, that is, utilizing the neural processes underlying action and perception (Barsalou, 2016; Soylu, 2016; Anderson, 2010).

Core to embodied cognition is the idea that cognition depends on knowing how to move in the world. This basic premise is not novel; in fact, it is readily found in pre-AI 
models of cognition. In particular, it exists in the theories of two major developmentalists, Jean Piaget and Lev Vygotsky. Piaget argued that humans learn through interacting (Piaget \& Inhelder, 1966). Arising from repeated interactions, knowing is not a "copy of reality" but a capacity to react to reality, thus "transforming it, apparently or effectively" (Piaget, 1968, p. 6). With the development of motor skills comes an increased capacity to interact, which drives the development of cognitive structures that, in turn, enable further interactions (Sheya \& Smith, 2010). Likewise placing action at the root of cognition, Vygotsky (1997) claimed that even abstract concepts, such as "various mathematical formulas... are related ultimately to particular residues of former movements now reproduced anew" (p. 162).

These classical ideas of human development are echoed in the embodied cognition notion of simulation, "the reenactment of perceptual, motor, and introspective states" (Barsalou 2008, p. 618). Essentially, simulation accounts posit that knowledge develops when the brain captures repeated "perceptual, motor, and introspective" patterns of an experience; when knowledge is needed, these multimodal patterns are simulated, or reactivated. The notion of knowledge as simulation is readily applicable to concrete concepts. For instance, Barsalou provides the example of sitting in a chair and developing the concrete concept category "chair." However, concepts that lack obvious sensorymotor contents, such as mathematical concepts, pose a classic and persistent challenge to theories of embodied cognition, with relatively little progress having been made in this direction over the last decade (compare Barsalou, 2010 with Barsalou, 2020). One of the central assumptions of embodied cognition-specifically, its presumed applicability to 
abstract concepts such as those found in mathematics, and not only to more concrete concepts-remains underexplored or even unexplored.

If physical interaction plays a role in the development of mathematical cognition, then this should, in principle, be observable in the course of a child's development. Indeed, existing empirical work points in this direction. Children with learning disabilities in mathematics tend to also perform worse on motor skill tasks, including visual-motor integration (Westendorp, Hartman, Houwen, Smith, \& Visscher, 2011; Pieters, Desoete, Roeyers, Vanderswalmen, \& Van Waelvelde, 2012). Fine motor skills in preschool and kindergarten have been shown to predict early academic mathematics achievements in first graders (Roebers, Röthlisberger, Neuenschwander, Cimeli, Michel, \& Jäger, 2014). In longitudinal research, fine motor skills showed a positive effect on the development of mathematical skills in kindergarten children and first graders (Luo, Jose, Huntsinger, \& Pigott, 2007). More recently, researchers examined the concurrent (Gashaj, Oberer, Mast, \& Roebers, 2019) and longitudinal (Gashaj, Oberer, Mast, \& Roebers, 2018) relationships between fine motor skills and mathematical abilities by controlling for executive functions and basic numerical skills. They found that nonsymbolic skills were related to fine motor skills concurrently, while math achievement was predicted indirectly through basic numerical skills. Finally, Barrocas et al. (2020) conducted a literature review of contributions of kindergarten fine motor skills to later numerical cognition, finding a "clear contribution of fine motor skills to numerical and mathematical abilities" (p. 9), with fine motor skills predicting counting, number system knowledge, number magnitude processing, and calculation ability. 


\section{Present Study}

In general, the available empirical evidence supports the interpretation of a positive relation between motor skills and mathematical achievement, with authors calling for further research in this area. The aim of the present study was to investigate the development of this relationship using a cross-sectional design, investigating fine motor skills and mathematical abilities with age-appropriate standard test batteries. To more closely examine whether and to what extent motor skills and (more formal) mathematical abilities co-develop, we focused on children at the cusp of formal schooling (age 6), at the start of formal schooling (age 8), and a few years into formal schooling (age 10). We expected a positive relationship between fine motor skills and mathematics throughout the development, and expected the relationship to change over time, that is, for the linear correlation to become weaker with age.

\section{Method}

\section{Participants}

Kindergarten. The sample consisted of 81 children (45 girls) in kindergarten, mean age of 6.24 years $(S D=0.34)$, mean BMI of $15.1(S D=1.27), 7$ left-handed.

Second Grade. The sample consisted of 81 children (39 girls) in second grade, mean age 8.2 years $(S D=0.28)$, mean BMI of $16.5(S D=2.17), 6$ left-handed.

Fourth Grade. The sample consisted of 96 children (41 girls) in fourth grade, mean age of 10.4 years $(S D=0.33)$. mean BMI of $17.7(S D=2.8), 12$ left-handed.

The majority of participating children were in middle to upper-middle class families in [blinded: a central European country]. For $69.9 \%$ of the participants, the language spoken at home was the local language, whereas $21.6 \%$ spoke other languages 
with both of their parents and $8.5 \%$ did not specify. All children were fluent in the local language and understood instructions.

\section{Measures}

Math Skills Proxy. As a proxy for math skills in Kindergarten, five tasks were used: symbolic and non-symbolic versions of a number line task and a magnitude comparison, as well as a subitizing task.

For the symbolic number line task, a computerized Number-to-Position (Laski and Siegler, 2007) adapted by Friso-van den Bos et al. (2014) was used. Participants saw a line on the screen with a start (1) and an endpoint (100). Then, specific numbers from 1 to 100 appeared in the upper half of the screen; participants had to point to where they thought the numbers belonged on the line. Alongside each number being shown on the screen $(2,4,9,11,14,17,23,26,31,38,44,45,52,59,61,66,73,78,84,86,92,99$ in randomized order), the numbers were read aloud by the experimenter. Due to their familiarity with touchscreens, children intuitively stayed on the line with their finger until the cursor moved to the indicated place. To minimize misinterpretations, the experimenter had the child confirm the cursor's position. The non-symbolic version of the number line task was similar, but realized with a cover story of a car filled with varying amounts of "drops of fuel" that equaled the number used for the symbolic version. Children estimated how far the car can drive with the amount of fuel shown. Accuracy, by using a linear fit measure, was used as the dependent variable on number line tasks.

Magnitude comparison skills were assessed using tasks originally developed by Laski and Siegler (2007) and adapted by Friso-van den Bos et al. (2014). In the symbolic 
version, children were asked to evaluate which of the two Arabic numbers shown was larger. In the non-symbolic version, the amount of dots displayed on each side of the screen were compared. One block with 33 trials was used in the symbolic version, and three blocks with 28 trials in the non-symbolic version. Examples used for the numbers and different ratios are: 10 vs 16 with a ratio of $0.63,12$ vs 16 with a ratio of 0.75 , and 14 vs 16 with a ratio of 0.88 . The ratios in the non-symbolic version were the same. There were more trials and blocks in the non-symbolic version in order to control for visual characteristics (e.g., dot size, density, total area; De Smedt, Noël, Gilmore, \& Ansari, 2013). Accuracy of magnitude skills, the percentage of correct trials, was used as the dependent variable on both magnitude comparison tasks.

Subitizing was assessed using pictures of the faces of two different dice. Children estimated the number of dots on both dice without counting. They answered verbally, once, as quickly as possible; after their answer was given, the next picture was shown. The task started with one practice trial followed by 9 experimental trials. Accuracy was used as the dependent variable.

Mathematical Skills. Mathematical skills were measured with standardized subtests of a curriculum-based paper-and-pencil math test (HRT 1-4; Haffner, Baro, Parzer, \& Resch, 2005). HRT 1-4 provides a differentiated and reliable overview of fundamental mathematical skills necessary for the acquisition of mathematical knowledge and more complex mathematical skills.

In second grade, the subtests were Addition, Subtraction, Sequences, and (In)equalities. For the Addition and Subtraction subtest, children solved computational tasks typically used in school. The subtest was stopped after $2.5 \mathrm{~min}$. The dependent 
variable was the sum of correctly solved trials out of a maximum of 40 . In the Sequences subtest, children had 3 minutes to analyze 20 sequences, that is, to determine the pattern of each sequence and write down the next three numbers in the sequence. Children received credit for each correct sequence. The dependent variable was the sum of correctly solved trials. The (In)equalities subtest involved simple comparisons of Arabic numbers (6 to be compared with 5) or simple comparisons of calculations (e.g., $100-3$ to be compared with 56). Children filled the empty space between the numbers or calculations with the signs $>$ (greater than), $<$ (less than), or = (equal to). 40 trials were presented over $2 \mathrm{~min}$. The dependent variable was the number of correctly solved trials minus half the incorrect trials. Mean raw scores, standard deviations, maxima and minima, and percentiles (per the test materials) are reported in table 1.

Table 1 Descriptive Statistics, Mathematical Skills

\begin{tabular}{lcccc}
\hline & Raw Score & Raw Score & Percentile & Percentile \\
& M (SD) & Min-Max & M & Min-Max \\
\hline Kindergarten & & & - & - \\
Subitizing & $5.53(2.49)$ & $0-9$ & - & - \\
Number Line NS & $0.69(0.17)$ & $0.01-0.94$ & - & - \\
Magnitude & $0.65(0.08)$ & $0.36-0.83$ & & - \\
Comparison NS & & & - & - \\
Number Line S & $0.42(0.29)$ & $0.00-0.97$ & & \\
Magnitude & $0.69(0.16)$ & $0.37-1.00$ & & \\
Comparison S & & &
\end{tabular}




\begin{tabular}{|c|c|c|c|c|}
\hline \multicolumn{5}{|l|}{ 2nd Grade } \\
\hline Addition & $19.84(3.75)$ & $10.00-27.00$ & 62.00 & $5.00-97.00$ \\
\hline Subtraction & $12.46(3.51)$ & $5.00-19.00$ & 42.72 & $3.00-86.00$ \\
\hline Sequences & $10.69(2.52)$ & $4.00-16.00$ & 65.92 & $14.00-99.70$ \\
\hline (In)Equalities & $17.16(4.84)$ & $4.00-30.00$ & 64.04 & $6.00-99.80$ \\
\hline \multicolumn{5}{|l|}{ 4th Grade } \\
\hline Addition & $27.55(4.28)$ & $16.00-37.00$ & 39.23 & $1.00-91.00$ \\
\hline Subtraction & $25.88(5.34)$ & $14.00-37.00$ & 42.32 & $2.00-99.00$ \\
\hline Sequences & $12.13(2.07)$ & $6.00-16.00$ & 31.02 & $4.00-87.00$ \\
\hline (In)Equalities & $27.66(5.94)$ & $13.00-40.00$ & 58.84 & $5.00-99.60$ \\
\hline
\end{tabular}

Note. $\mathrm{S}=$ Symbolic; $\mathrm{NS}=$ Nonsymbolic

Fine Motor Skills. To assess fine motor skills, three tasks of the manual dexterity subscale from the Movement Assessment Battery for Children (M-ABC-2; Petermann, 2009) were carried out according to the test manual. Age appropriate tests of the assessment battery were used at the respective ages-that is, Threading Beads, Posting Coins, and Drawing Trail 1 in Kindergarten; Placing Pegs, Threading Lace, and Drawing Trail 2 in second grade; Turning Pegs, Triangle with Nuts and Bolts, and Drawing Trail 3 in fourth grade.

For Threading Beads, kindergarteners threaded twelve cubic beads into a red lace equipped with a threading device. Kindergarteners held the lace with one hand and picked the beads with the other. The task was solved twice, as fast as possible, first with 
the dominant hand and then with the non-dominant hand. The counterpart of this task for the $2^{\text {nd }}$ graders-Threading Lace-followed the same logic; however, instead of the beads, a plastic board was used to thread a lace through. For the $4^{\text {th }}$ graders, the task differed. The goal was to build a Triangle with Nuts and Bolts. The completed triangle was made visible to the participants, who were instructed to build the triangle with the available nuts and bolts as fast as possible. The dependent variable was time to task completion.

For Posting Coins, kindergarteners were asked to put twelve plastic coins into a coin bank box. Kindergarteners were instructed to hold the box with one hand and insert the coins (one coin at a time) with the other. The task was solved twice, first with the dominant hand inserting the coins and then with the non-dominant hand. The $2^{\text {nd }}$ graders were asked to insert pegs into holes on a board. Similar to the Kindergarteners task, $2^{\text {nd }}$ graders were asked to first use the dominant hand to complete the task, and then repeat the procedure with the non-dominant hand. The equivalent of this task for the $4^{\text {th }}$ graders was Turning Pegs. In addition to inserting the pegs into holes, $4^{\text {th }}$ graders also had to turn all pegs once inserted, so as to additionally match specific color schemes. The procedure was done twice, once with the dominant hand and once with the non-dominant one. The dependent variable was time to task completion.

For the Drawing Trail task, children used an exercise sheet with a sketching of a path with two bicycles at the start, a tunnel in the middle, and a house at the end of the path. Children were instructed to draw a line following the path from the bicycles, through the tunnel, and to the house in a single attempt and without crossing the boundaries of the path. Task difficulty increased with age and was achieved by adding 
curves and turns and a narrower path for the older children. The dependent variable was the number of errors.

Mean raw scores, standard deviations, maxima and minima, as well as percentiles (per the test materials) are reported in table 2.

Table 2 Descriptive Statistics, Fine Motor Skills

\begin{tabular}{|c|c|c|c|c|}
\hline & $\begin{array}{c}\text { Raw Score } \\
\text { M (SD) }\end{array}$ & $\begin{array}{l}\text { Raw Score } \\
\text { Min-Max }\end{array}$ & $\begin{array}{c}\text { Percentile } \\
\text { M (SD) FMS }\end{array}$ & $\begin{array}{l}\text { Percentile } \\
\text { Min-Max }\end{array}$ \\
\hline \multicolumn{5}{|l|}{ Kindergarten } \\
\hline Posting Coins D & $18.52(2.27)$ & $12.62-25.30$ & 50 & $2.00-95.00$ \\
\hline Posting Coins ND & $19.68(2.44)$ & $15.01-25.80$ & 50 & $5.00-95.00$ \\
\hline Threading Beads & $38.29(7.25)$ & $27.43-65.00$ & 69 & $1.00-98.00$ \\
\hline Drawing Trail 1 & $4.33(3.35)$ & $0-16$ & 8 & $0.10-75.00$ \\
\hline \multicolumn{5}{|l|}{ 2nd Grade } \\
\hline Placing Pegs D & $26.95(3.82)$ & $19.00-39.00$ & 56 & $1.00-99.90$ \\
\hline Placing Pegs ND & $33.64(7.55)$ & $20.00-68.00$ & 50 & $2.00-95.00$ \\
\hline Threading Lace & $24.88(4.44)$ & $16.00-35.90$ & 63 & $5.00-99.00$ \\
\hline Drawing Trail 2 & $1.85(1.84)$ & $0.00-8.00$ & 25 & $0.10-75.00$ \\
\hline \multicolumn{5}{|l|}{ 4th Grade } \\
\hline Turning Pegs D & $20.07(3.56)$ & $13.00-38.00$ & 50 & $0.10-99.00$ \\
\hline Turning Pegs ND & $22.02(3.5)$ & $15.00-33.00$ & 56 & $5.00-98.00$ \\
\hline
\end{tabular}


Triangle

Drawing Trail 3
$39.89(10.16)$

$5.22(3.95)$
$22.00-69.00$

$0.00-21.00$
50

12
$2.00-99.60$

$0.10-84.00$

Note. $\mathrm{D}=$ Dominant Hand $\mathrm{ND}=$ Nondominant Hand

\section{Procedure}

The research project was approved by the local Ethics Committee which follows APA guidelines and the principles of the Declaration of Helsinki. Written informed consent was obtained from the children's parents. The tests were completed in two sessions, each lasting 45 minutes. The computer-based tasks were administered on a laptop (Lenovo 3000 N200 with a 15.4 WXGA screen, aspect ratio of 16:10, and a resolution of 1,280 x 800 pixels) located in a separate room; the motor skills tasks were conducted together in the school's gym by means of a station circuit. The paper-pencil mathematical tests were administered during a school lesson with the whole class. The children were rewarded with a small gift and the teachers received a small monetary donation.

\section{Results}

To explore the relationship between fine motor skills and mathematical skills at different time points, Bayesian correlations were performed. We report the Pearson correlation coefficient (r), and the Bayes Factor (BF). To preserve the variability of children's skills, raw scores were used for this analysis (see Roebers et al., 2014; Gashaj, Oberer, Mast, \& Roebers, 2018). JASP was used for all analyses (JASP Team, 2020). Associations between fine motor and math performances can be partly understood by considering the correlations between individual components. 
In tables below, $\mathrm{BF}_{10}$ is the likelihood of the data under the null hypothesis (i.e., no difference) divided by the likelihood of the data under the alternative. Thus, values greater than 1 favor the alternative hypothesis, whereas values lower than 1 favor the null hypothesis. The advantage of Bayesian over classical (frequentist) statistics is that the Bayes factor provides a measure of the strength of evidence both for and against the alternative hypothesis, whereas $p$-values are more prone to misinterpretation (Nuzzo, 2017). Table 3 can be consulted for the correlations between the fine motor skills and math skills in kindergarteners.

Table 3 Bayesian Pearson Correlations, Kindergarten

\begin{tabular}{|c|c|c|c|c|c|c|c|c|c|c|}
\hline Variable & & Coins D & $\begin{array}{l}\text { Coins } \\
\text { ND }\end{array}$ & Beads & Trail & Subitizing & $\begin{array}{l}\text { Number } \\
\text { line } \\
\text { NS }\end{array}$ & $\begin{array}{l}\text { MC } \\
\text { NS }\end{array}$ & $\begin{array}{l}\text { Number } \\
\text { line } \\
\mathrm{S}\end{array}$ & $\begin{array}{l}\text { MC } \\
\text { S }\end{array}$ \\
\hline \multirow[t]{2}{*}{ 1. Coins D } & $\mathrm{r}$ & - & & & & & & & & \\
\hline & $\mathrm{BF}_{10}$ & - & & & & & & & & \\
\hline \multirow[t]{2}{*}{ 2. Coins ND } & $\mathrm{r}$ & 0.23 & - & & & & & & & \\
\hline & $\mathrm{BF}_{10}$ & 2.13 & - & & & & & & & \\
\hline \multirow[t]{2}{*}{ 3. Beads } & $\mathrm{r}$ & $0.37 * *$ & $0.46^{* * *}$ & - & & & & & & \\
\hline & $\mathrm{BF}_{10}$ & 87.09 & 2637.51 & - & & & & & & \\
\hline \multirow[t]{2}{*}{ 4. Trail } & r & $0.25^{\star}$ & 0.20 & 0.19 & - & & & & & \\
\hline & $\mathrm{BF}_{10}$ & 3.6 & 1.19 & 1.13 & - & & & & & \\
\hline \multirow[t]{2}{*}{ 5. Subitizing } & $\mathrm{r}$ & $-0.27^{\bullet}$ & -0.12 & $-0.38 * * *$ & -0.16 & - & & & & \\
\hline & $\mathrm{BF}_{10}$ & 5.08 & 0.43 & 83.60 & 0.68 & - & & & & \\
\hline \multirow[t]{2}{*}{ 6. Numberline NS } & $\mathrm{r}$ & 0.13 & 0.23 & -0.03 & 0.03 & 0.09 & - & & & \\
\hline & $\mathrm{BF}_{10}$ & 0.07 & 0.05 & 0.17 & 0.11 & 0.30 & - & & & \\
\hline
\end{tabular}




$\begin{array}{llllllllllll}\text { 7. MC NS } & \mathrm{r} & -0.03 & 0.10 & 0.02 & -0.02 & 0.23 & 0.35^{* *} & - & & \\ & & \mathrm{BF}_{10} & 0.17 & 0.08 & 0.12 & 0.16 & 1.88 & 37.99 & - & & \\ \text { 8. Numberline S } & \mathrm{r} & 0.10 & 0.11 & -0.05 & 0.05 & 0.00 & 0.31^{*} & 0.24 & - & \\ & \mathrm{BF}_{10} & 0.08 & 0.07 & 0.21 & 0.10 & 0.14 & 11.99 & 2.57 & - & \\ & & & & & & & & & & & \\ \text { 9. MC S } & \mathrm{r} & -0.07 & -0.02 & 4.581 \mathrm{e}^{-4} & -0.05 & 0.02 & 0.26^{*} & 0.10 & 0.40^{* * *} & - \\ & \mathrm{BF}_{10} & 0.24 & 0.17 & 0.14 & 0.20 & 0.16 & 3.88 & 0.34 & 188.10 & -\end{array}$

Note. $\mathrm{r}=$ Pearson's; ${ }^{-\mathrm{BF}_{10}}>3, * \mathrm{BF}_{10}>10, * * \mathrm{BF}_{10}>30, * * * \mathrm{BF}_{10}>100 ; \mathrm{S}=$ Symbolic; $\mathrm{NS}=$ Nonsymbolic; $\mathrm{D}=$ Dominant Hand; $\mathrm{ND}=$ Nondominant Hand; in case of domain-specific correlations the alternative hypothesis was "There is a positive correlation"; in case of domain-general correlations the alternative hypothesis was "There is a negative correlation", due to speed tasks and error measures in the fine motor skill tasks.

$\mathrm{BF}_{10}$ values between 0.33 and 3 are inconclusive (Nuzzo, 2017). All significant correlations are therefore above the inconclusiveness interval. Recall that the fine motor tasks measures were of speed or error, and number lines were of percentage of absolute error (thus, lower scores are better); consequently, a negative $r$ value indicates a positive relationship between fine motor skills and mathematical skills (except for number lines).

Next, table 4 can be consulted for the correlations between the fine motor skills and math skills in 2nd graders.

Table 4 Bayesian Pearson Correlations 2nd Grade

\begin{tabular}{|c|c|c|c|c|c|c|c|c|c|}
\hline \multicolumn{2}{|l|}{ Variable } & \multirow{2}{*}{$\begin{array}{l}\text { Pegs D } \\
-\end{array}$} & \multirow[t]{2}{*}{$\begin{array}{l}\text { Pegs } \\
\text { ND }\end{array}$} & \multirow[t]{2}{*}{ Thread } & \multirow[t]{2}{*}{ Trail } & \multirow[t]{2}{*}{ Addition } & \multirow[t]{2}{*}{ Subtraction } & \multirow[t]{2}{*}{ Sequences } & \multirow[t]{2}{*}{$\begin{array}{l}\text { (In) } \\
\text { Equalities }\end{array}$} \\
\hline 1. Pegs D & $\mathrm{r}$ & & & & & & & & \\
\hline & $\mathrm{BF}_{10}$ & - & & & & & & & \\
\hline \multirow[t]{2}{*}{ 2. Pegs ND } & $\mathrm{r}$ & $0.36^{* *}$ & - & & & & & & \\
\hline & $\mathrm{BF}_{10}$ & 57.59 & - & & & & & & \\
\hline
\end{tabular}




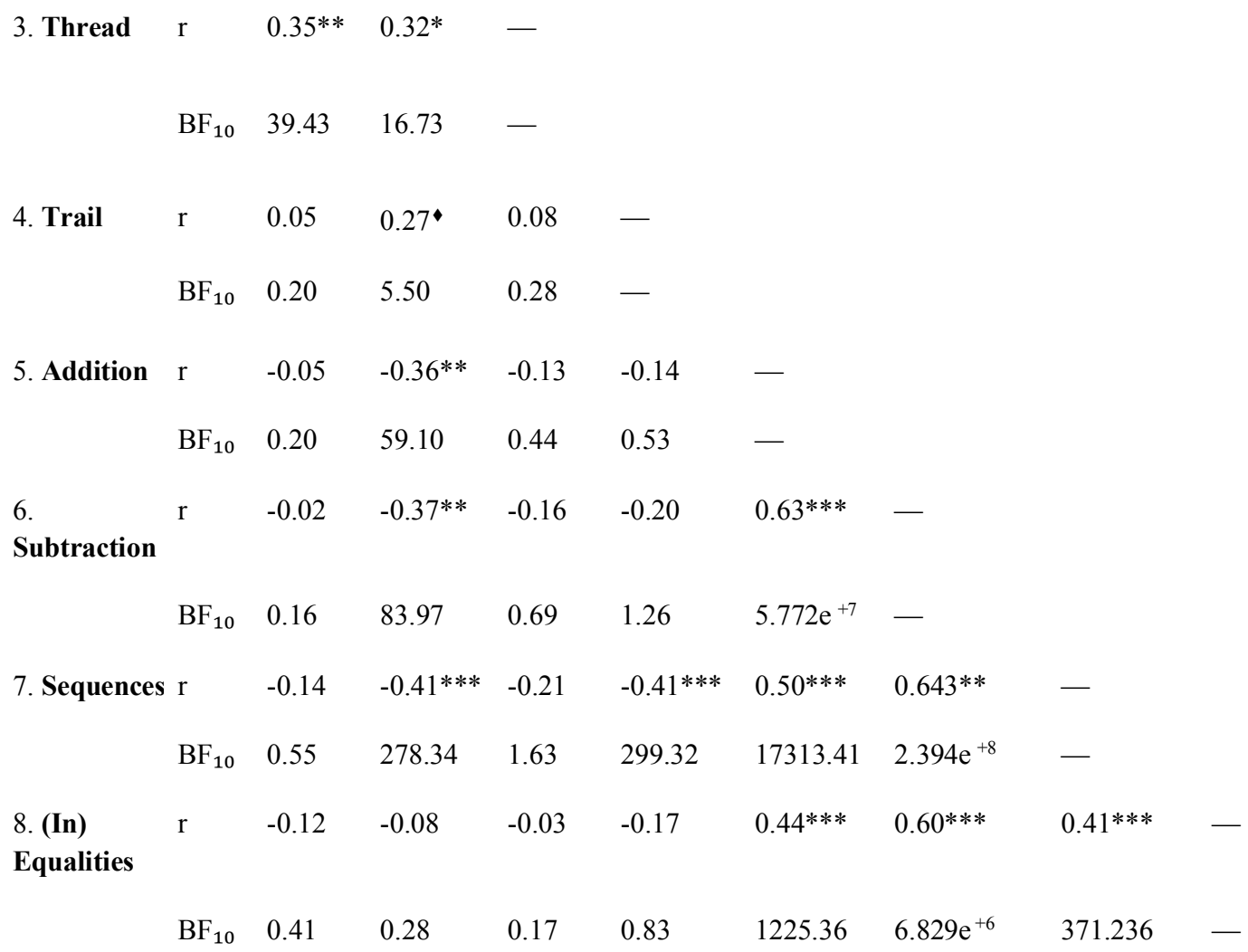

Note. $\mathrm{r}=$ Pearson's; ${ }^{\star} \mathrm{BF}_{10}>3, * \mathrm{BF}_{10}>10, * * \mathrm{BF}_{10}>30, * * * \mathrm{BF}_{10}>100 ; \mathrm{S}=$ Symbolic; $\mathrm{NS}=$ Nonsymbolic; $\mathrm{D}=$ Dominant Hand; $\mathrm{ND}=$ Nondominant Hand; in case of domain-specific correlations the alternative hypothesis was "There is a positive correlation"; in case of domain-general correlations the alternative hypothesis was "There is a negative correlation", due to speed tasks and error measures in the fine motor skill tasks.

Finally, for the correlations between fine motor skills and math skills in 4th graders, see table 5 .

Table 5 Bayesian Pearson Correlations 4th Grade

\begin{tabular}{lllllllll}
\hline Variable & & Pegs D & $\begin{array}{c}\text { Pegs } \\
\text { ND }\end{array}$ & Triangle & Trail & Addition & Subtraction Sequences $\begin{array}{c}\text { (In) } \\
\text { Equalities }\end{array}$ \\
\hline 1. Pegs D & $\mathrm{r}$ & - & & & & & \\
& $\mathrm{BF}_{10}$ & - & & & & & \\
& & & & & & \\
2. Pegs ND & $\mathrm{r}$ & $0.34^{* *}$ & - & & & &
\end{tabular}




\begin{tabular}{|c|c|c|c|c|c|c|c|c|}
\hline \multirow{3}{*}{ 3. Triangle } & $\mathrm{BF}_{10}$ & 82.60 & \multicolumn{6}{|l|}{ - } \\
\hline & $\mathrm{r}$ & 0.17 & $0.29 *$ & - & & & & \\
\hline & $\mathrm{BF}_{10}$ & 0.95 & 15.77 & - & & & & \\
\hline \multirow[t]{2}{*}{ 4. Trail } & $\mathrm{r}$ & -0.01 & $0.31 * *$ & 0.17 & - & & & \\
\hline & $\mathrm{BF}_{10}$ & 0.12 & 26.70 & 0.88 & - & & & \\
\hline \multirow[t]{2}{*}{ 5. Addition } & $\mathrm{r}$ & -0.00 & -0.09 & 0.04 & -0.06 & - & & \\
\hline & $\mathrm{BF}_{10}$ & 0.13 & 0.31 & 0.10 & 0.22 & - & & \\
\hline \multirow[t]{2}{*}{ 6. Subtraction } & $\mathrm{r}$ & -0.06 & -0.02 & 0.05 & -0.12 & $0.68 * * *$ & - & \\
\hline & $\mathrm{BF}_{10}$ & 0.20 & 0.15 & 0.09 & 0.41 & $3.534 \mathrm{e}^{+11}$ & - & \\
\hline \multirow[t]{2}{*}{ 7. Sequences } & $\mathrm{r}$ & -0.05 & -0.14 & 0.05 & -0.25 & $0.47 * * *$ & $0.61 * * *$ & - \\
\hline & $\mathrm{BF}_{10}$ & 0.19 & 0.59 & 0.09 & 2.61 & 25594.08 & $3.216 \mathrm{e}^{+8}$ & - \\
\hline \multirow[t]{2}{*}{$\begin{array}{l}8 . \text { (In) } \\
\text { Equalities }\end{array}$} & $\mathrm{r}$ & -0.18 & -0.07 & 0.06 & -0.17 & $0.55^{* * *}$ & $0.65^{* * *}$ & $0.53 * * *$ \\
\hline & $\mathrm{BF}_{10}$ & 1.13 & 0.24 & 0.09 & 0.86 & $2.956 \mathrm{e}^{+6}$ & $2.688 \mathrm{e}^{+10}$ & 874177.90 \\
\hline
\end{tabular}

Note. $\mathrm{r}=$ Pearson's; ${ }^{\star} \mathrm{BF}_{10}>3, * \mathrm{BF}_{10}>10, * * \mathrm{BF}_{10}>30, * * * \mathrm{BF}_{10}>100 ; \mathrm{S}=$ Symbolic; $\mathrm{NS}=$ Nonsymbolic; $\mathrm{D}=$ Dominant Hand; ND = Nondominant Hand; in case of domain-specific correlations the alternative hypothesis was "There is a positive correlation"; in case of domain-general correlations the alternative hypothesis was "There is a negative correlation", due to speed tasks and error measures in the fine motor skill tasks.

The four tasks for fine motor skills exhibited low to moderate evidence favoring the existence of positive relationships, with higher correlations in Kindergarteners than 2nd and 4th graders. Surprisingly, there was no evidence of a positive relationship between the Kindergarteners' math proxy tasks. In contrast, in 2nd and 4th grade, all math tasks correlated highly and positively as expected, with Bayes factors indicating extreme evidence for the alternative hypothesis.

An interesting pattern emerged in the associations between the fine motor and math tasks. In Kindergarten the relations between fine motor skills (Coins with the dominant 
hand and Beads) and subitizing skills were positive and moderately to strongly supported by the Bayes Factor; while in 2nd grade, fine motor skills (Pegs task, again, but with the non-dominant hand only, and Trail task) were positively related to addition, subtraction and sequences in $2^{\text {nd }}$ grade with higher support of evidence from the Bayes Factor. In $4^{\text {th }}$ grade, however, the correlations between fine motor skills and math ability were not supported by the Bayes Factors.

\section{Discussion}

\section{Summary of results}

The aim of the present study was to investigate the development of the relationship between fine motor skills and mathematical skills using a cross-sectional design and ageappropriate standard test batteries. To more closely examine whether and to what extent motor skills and (more formal) mathematical abilities co-develop, we focused on children at the cusp of formal schooling (age 6), at the start of formal schooling (age 8), and a few years into formal schooling (age 10).

The observed relations between fine motor skill tasks and mathematical tasks were the following. Recall that a lower value means better performance on the FMS tasks; therefore, a negative $\mathrm{r}$ is indicative of a positive relationship.

In kindergarten, we found positive relations between these fine motor skill tasks and mathematical tasks:

i) Subitizing and Coins (dominant hand), $\mathrm{r}=-0.27, \mathrm{BF}_{10}=5.08$;

ii) Subitizing and Beads, $\mathrm{r}=-0.38, \mathrm{BF}_{10}=83.60$;

In 2nd grade, we found positive relations between:

i) Addition and Pegs (non-dominant hand), $\mathrm{r}=-0.36, \mathrm{BF}_{10}=59.10$; 
ii) Subtraction and Pegs (non-dominant hand), $\mathrm{r}=-0.37, \mathrm{BF}_{10}=83.97$;

iii) Sequences and Pegs (non-dominant hand), $\mathrm{r}=-0.41, \mathrm{BF}_{10}=278.34$;

iv) Sequences and Trail, $\mathrm{r}=-0.41, \mathrm{BF}_{10}=299.32$.

In 4 th grade, we found no positive relations between the fine motor skill tasks and mathematical tasks. Overall, our expectation that fine motor skills and math abilities would have a positive relationship that decreases with age was partially supported, with some evidence at age 6 , the strongest evidence for a relationship appearing at age 8 , and no evidence for a relationship at age 10 .

One surprising observation is that in kindergarten only the dominant hand task appeared positively related to mathematical ability, while in 2 nd grade it was only the non-dominant hand task. Research indicates that very young children, 3- to 5-year-olds, demonstrate weak, inconsistent hand preference tendencies, using both hands to explore space, whereas children in the 7- to 10-year-old range demonstrate an increased pattern of reliance on the preferred hand; finally, a strong reliance on the preferred hand drops between the ages of 10 and 12, and performance differences between the two hands become smaller again (Scharoun \& Bryden, 2014). Thus, one explanation for the changing role of handedness with age in our study is that-in addition to observing the expected decrease in the relationship between motor skills and math ability with age-we are also observing the natural developmental trajectory of handedness.

To summarize, we expected to find positive relationships between fine motor skills and mathematical abilities throughout the age range of the sample, and expected the relationship to change over time, with a decreasing correlation coefficient and lower Bayes Factors with increasing age. One reason to expect a decrease is due to the 
implications of the aforementioned notion of simulation, "the reenactment of perceptual, motor, and introspective states." Experience is necessary to develop simulations; a core premise of embodiment is that this experience is initially grounded in physical interaction. At some point in development, however, the relevant interactions are sufficiently captured as sensorimotor processes, such that cognitive processes can make use of them as needed (Soylu, 2016). Thus, among younger children we would expect to see a stronger relationship in this regard-as the relevant sensorimotor processes are still inadequately captured.

Interestingly, fine motor skills were strongly related to mathematical abilities in $2^{\text {nd }}$ grade, when children learn about operations. Later, in $4^{\text {th }}$ grade, the same skills seem not to share any variance with each other. This might be due to the automatization of fine motor skills. The automatization of basic fine motor skills allows for resources to open up and become available for more complex cognitive activities (see Christensen, 2004). Another reason we did not see a relationship in $4^{\text {th }}$ grade could be the automatization of mathematical skills such as mathematical operations. Finger-counting strategies constitute a natural scaffold in early schooling years (for an overview, see Barrocas, Roesch, Gawrilow, \& Moeller, 2020). However, over time children are explicitly requested to no longer use their hands for mathematical activity. Having developed sufficient sensorimotor processing at that point, the observable relationship may turn inwards, with children imagining hands or finger movement until this activity too becomes automatic. At this point, the physical performance of fine motor skills themselves would no longer be related to mathematical performance. Motor development is unique in the sense that its mechanisms of development can be directly observed 
(Adolph \& Berger, 2006). When those changes are not observable anymore, children might have automatized certain skills.

Taken together, our results seem to argue in favor of a positive relationship between fine motor skills and mathematics that changes throughout the development, that is, becomes weaker with age.

\section{Limitations}

A limitation of the present study is the cross-sectional design, which cannot capture the developmental changes of individual children. Thus, we can only assume that the results are not biased by a cohort effect. While more challenging to implement, longitudinal studies would provide an advantage.

The numerical tasks used in Kindergarten did not correlate with each other. It might be difficult to compare the relationship of numerical skills and fine motor skills to the relationship of those skills at different ages in primary school. Unless there is a more standardized way to assess numerical skills in Kindergarten - where the subtests would correlate with each other and measure the underlying concept - we can only speculate about the development of the relationship between fine motor skills and numerical skills. In order to avoid this dilemma, and still observe the development of the relationship between fine motor skills and mathematical skills, researchers should consider including 1st graders in their studies.

For the present study, the linear fit of a symbolic and a non-symbolic number line task was used. The linear fit has previously been found to correlate with mathematical achievement (Simms, Clayton, Cragg, Gilmore, \& Johnson, 2016). However, other measures such as the percent absolute error, do not always correlate to other basic 
numerical skills or mathematical achievement (Link, Huber, Nuerk, \& Moeller, 2014).

Furthermore, different number line tasks (bounded, unbounded) require different solving strategies (Slusser, Santiago, \& Barth, 2013; Dietrich, Huber, Dackermann, Moeller, \& Fischer, 2016) which could lead to other relational results (Slusser, \& Barth, 2017). Thus, it would be important to investigate various indices and see if there are relations between those measures and fine motor skills.

Another limitation worth mentioning are the unexpectedly low percentiles in drawing trail tasks. Our three samples drastically underperformed when compared to the norms. One possible explanation is that the norm and the sample do not come from the same country, despite using the same language. It is possible that the norms thus reflect differences in curricular focus between the countries. Another possibility is that the experimenters were unduly critical when scoring the task and overcounted the errors on this particular task.

\section{Conclusions and future work}

For future work, we suggest addressing the aforementioned limitations. Research studies investigating the development of the relationship between (fine) motor skills and mathematical abilities should be conducted with standardized (norm-referenced) test batteries that have been proven to be valid and reliable. Future studies should additionally include tests of gross motor skills and other types of motor skills (e.g. visuo-motor skills) for a more differentiated evaluation of the relationship between motor and mathematical abilities.

For a better understanding of the developmental change of the relationship between fine motor skills and mathematical skills, future work should add more age 
groups into their investigation, and even better design for a longitudinal microgenetic study which follows the children more densely over the years.

To sum up, the present study is among the first to document the development of the relationship between fine motor skills and mathematical abilities in the ages between 6 and 10.5. The present findings contribute to not only basic research, but hold practical implications for intervention and remediation programs. By adding spatial and motor aspects to mathematical tasks, training involving whole body movement or specific finger movements may be supported. In this context, there is a need for future research to examine whether fine motor skills can serve as an early marker of risk detection in the development of mathematical skills.

\section{Acknowledgments}

We would like to thank all children, parents, teachers, and schools for participating. We would also like to thank the research assistants and students who helped with data collection. Special thanks also to Dr. Krzysztof Cipora for fruitful conversations about Bayesian Analysis, and the test center at the University of Bern for granting us access to the Manuals of the used Test Batteries. 


\section{References}

Adolph, K. E., \& Berger, S. E. (2006). Motor development. In D. Kuhn \& R. Siegler (Eds.). Handbook of child psychology. Cognition, perception, and language (Vol. 2, pp. 161-213). New York: Wiley.

Anderson, M. L. (2010). Neural reuse: A fundamental organizational principle of the brain. Behavioral and brain sciences, 33(4), 245-266. doi:10.1017/S0140525X10000853.

Barrocas, R., Roesch, S., Gawrilow, C., \& Moeller, K. (2020). Putting a finger on numerical development-Reviewing the contributions of kindergarten finger gnosis and fine motor skills to numerical abilities. Frontiers in Psychology, 11, 1012. doi:10.3389/fpsyg.2020.01012.

Barsalou, L. W. (2008). Grounded cognition. Annual Review of Psychology, 59, 617-645. doi:10.1146/annurev.psych.59.103006.093639.

Barsalou, L. W. (2010). Grounded cognition: Past, present, and future. Topics in cognitive science, 2(4), 716-724. doi:10.1111/j.1756-8765.2010.01115.x.

Barsalou, L. W. (2016). Situated conceptualization: Theory and applications. In Y. Coello \& M. H. Fischer (Eds.), Foundations of embodied cognition, Volume 1: Perceptual and emotional embodiment (pp. 11-37). East Sussex, UK: Psychology Press.

Barsalou, L. W. (2020). Challenges and opportunities for grounding cognition. Journal of Cognition, 3(1). doi:10.5334/joc. 116. 
Christensen, C. A. (2004). Relationship between orthographic-motor integration and computer use for the production of creative and well-structured written text. British Journal of Educational Psychology, 74, 551-564.

Dietrich, J. F., Huber, S., Dackermann, T., Moeller, K., \& Fischer, U. (2016). Place-value understanding in number line estimation predicts future arithmetic performance. British Journal of Developmental Psychology. doi: 10.1111/bjdp.12146.

Friso-van den Bos, I. Kolkman, M. E., Kroesbergen, E. H., \& Leseman, P. P. M. (2014). Explaining variability: Numerical representations in 4- to 8-year-old children. Journal of Cognition and Development, 15, 325-344. doi: 10.1080/15248372.2012.742900.

Gashaj, V., Oberer, N., Mast, F. W., and Roebers, C. M. (2018). The relation between executive functions, fine motor skills, and basic numerical skills and their relevance for later mathematics achievement. Early Education and Development, 30, 913926. doi: 10.1080/10409289.2018.1539556.

Gashaj, V., Oberer, N., Mast, F. W., and Roebers, C. M. (2019). Individual differences in basic numerical skills: the role of executive functions and motor skills. Journal of Experimental Child Psychology, 182, 187-195. doi: 10.1016/j.jecp.2019.01.021.

Gesell, A., \& Thompson, H. A. (1934). Infant behaviour: Its genesis and growth. New York, NY: McGraw-Hill.

Grissmer, D., Grimm, K., Aiyer, S. M., Murrah, W. M., \& Steele, J. S. (2010). Fine motor skills and early comprehension of the world: two new school readiness indicators. Developmental Psychology, 46(5), 1008-1017. Doi:10.1037/a0020104. JASP Team (2020). JASP (Version 0.14.1) [Computer software]. Retrieved from 
https://jasp-stats.org.

Laski, E. V., \& Siegler, R. S. (2007). Is 27 a big number? Correlational and causal connections among numerical categorization, number line estimation, and numerical magnitude comparison. Child Development, 78, 1723-1743. doi: 10.1111/j.1467-8624.2007.01087.x.

Link, T., Huber, S., Nuerk, H., \& Moeller, K. (2014). Unbounding the mental number line-New evidence on children's spatial representation of numbers. Frontiers in Psychology, 4, 1021, 203-214. doi: 10.3389/fpsyg.2013.01021

Luo, Z., Jose, P. E., Huntsinger, C. S., \& Pigott, T. D. (2007). Fine motor skills and mathematics achievement in East Asian American and European American kindergartners and first graders. British Journal of Developmental Psychology, 25(4), 595-614. doi: 10.1348/026151007X185329.

Nuzzo, R. L. (2017). An Introduction to Bayesian Data Analysis for Correlations. PM \& R: The Journal of Injury, Function, and Rehabilitation, 9, 1278 - 1282. doi:10.1016/j.pmrj.2017.11.003.

Oberer, N., Gashaj, V., \& Roebers, C. M. (2017). Motor skills in kindergarten: Internal structure, cognitive correlates and relationships to background variables. Human Movement Science, 52, 170-180. doi:10.1016/j.humov.2017.02.002.

Petermann, F. (2009b). Movement Assessment Battery for Children-2 (M-ABC-2) (2. Edition, german adaption.). Frankfurt/M.: Pearson Assessment.

Piaget, J. (1968). Quantification, Conservation, and Nativism: Quantitative evaluations of children aged two to three years are examined. Science, 162(3857), 976-979. 
Piaget, J., \& Inhelder, B. (1966). La psychologie de l'enfant [the psychology of the child]. Paris, France: Presses Universitaires de France.

Pieters, S., Desoete, A., Roeyers, H., Vanderswalmen, R., \& Van Waelvelde, H. (2012). Behind mathematical learning disabilities: What about visual perception and motor skills? Learning and Individual Differences, 22(4), 498-504. doi:

10.1016/j/lindif.2012.03.014.

Roebers, C. M., Röthlisberger, M., Neuenschwander, R., Cimeli, P., Michel, E., \& Jäger, K. (2014). The relation between cognitive and motor performance and their relevance for children's transition to school: A latent variable approach. Human Movement Science, 33, 284-297. doi:10.1016/j.humov.2013.08.011.

Simms, V., Clayton, S., Cragg, L., Gilmore, C., \& Johnson, S. (2016). Explaining the relationship between number line estimation and mathematical achievement: the role of visuomotor integration and visuospatial skills. Journal of experimental child psychology, 145, 22-33. doi: 10.1016/j.jecp.2015.12.004.

Scharoun, S. M., \& Bryden, P. J. (2014). Hand preference, performance abilities, and hand selection in children. Frontiers in Psychology, 5, 82. doi: 10.3389/fpsyg.2014.00082.

Sheya, A., \& Smith, L. B. (2010). Development through sensorimotor coordination. In J. Stewart, O. Gapenne, \& E. A. Di Paolo (Eds.), Enaction (pp. 123-143). The MIT Press. doi:10.7551/mitpress/9780262014601.003.0005.

Slusser, E. B., Santiago, R. T., \& Barth, H. C. (2013). Developmental change in numerical estimation. Journal of Experimental Psychology: General, 142(1), 193. doi: $10.1037 / \mathrm{a} 0028560$. 
Slusser, E., \& Barth, H. (2017). Intuitive proportion judgment in number-line estimation: Converging evidence from multiple tasks. Journal of Experimental Child Psychology, 162, 181-198.

Soylu, F., Lester Jr, F. K., \& Newman, S. D. (2018). You can count on your fingers: The role of fingers in early mathematical development. Journal of Numerical Cognition, 4(1), 107-135. doi:10.5964/jnc.v4i1.85.

Vygotsky, L. (1926). Educational Psychology; Silverman, R., Translator; CRC Press: Boca Raton, FL, USA, 1997.

Van der Fels, I. M., Te Wierike, S. C., Hartman, E., Elferink-Gemser, M. T., Smith, J., \& Visscher, C. (2015). The relationship between motor skills and cognitive skills in 4-16 year old typically developing children: A systematic review. Journal of science and medicine in sport, 18(6), 697-703. doi:10.1016/j.jsams.2014.09.007.

Wassenberg, R., Feron, F. J., Kessels, A. G., Hendriksen, J. G., Kalff, A. C., Kroes, M., ... \& Vles, J. S. (2005). Relation between cognitive and motor performance in 5-to 6-year-old children: Results from a large-scale cross-sectional study. Child development, 76(5), 1092-1103. doi:10.1111/j.1467-8624.2005.00899.x

Westendorp, M., Hartman, E., Houwen, S., Smith, J., \& Visscher, C. (2011). The relationship between gross motor skills and academic achievement in children with learning disabilities. Research in developmental disabilities, 32(6), 2773-2779. doi:10.1016/j.ridd.2011.05.032. 